\title{
CITIZEN PARTICIPATION IN NEWS
}

\section{An analysis of the landscape of online journalism}

\author{
Jonathan Scott, David Millard, and Pauline Leonard
}

\begin{abstract}
The process of producing news has changed significantly due to the advent of the Web, which has enabled the increasing involvement of citizens in news production. This trend has been given many names, including participatory journalism, produsage, and crowd sourced journalism, but these terms are ambiguous and have been applied inconsistently, making comparison of news systems difficult. In particular it is problematic to distinguish the levels of citizen involvement, and therefore the extent to which news production has genuinely been opened up. In this paper we perform an analysis of 32 online news systems, comparing them in terms of how much power they give to citizens at each stage of the news production process. Our analysis reveals a diverse landscape of news systems and shows that they defy simplistic categorisation, but it also provides the means to compare different approaches in a systematic and meaningful way. We combine this with four case studies of individual stories to explore the ways that news stories can move and evolve across this landscape. Our conclusions are that online news systems are complex and interdependent, and that most do not involve citizens to the extent that the terms used to describe them imply.
\end{abstract}

KEYWORDS audience participation; citizen journalism; citizen participation; news production; online journalism; online media

\section{Introduction}

In 1965 Galtung \& Ruge investigated the first half of what they called the "chain of news communication", the process by which a news image is produced from a world event. The complete chain had five stages: world events, media perception, media image, personal perception, and personal image. However, in the years since their work was published the news industry has changed significantly (Thurman \& Hermida 2010; Bowman \& Willis 2003, 5-13). Whereas it was once the domain of journalistic gatekeepers deciding what news was fit to be heard, much news is now defined by interaction with readers. This makes the modern chain of news communication far more complex than that which existed in 1965 given the many levels of journalist and public interpretation for any single event. This new process of news production has been given many names including produsage, participatory journalism, and crowd-sourced journalism. These imply some level of public participation in news-making but are nonspecific as to where this occurs and to what extent it matters to the final product.

The question of the involvement of citizens in news production is important. The news media has frequently been described as "the fourth estate" (Schultz 1998), with a free press being a cornerstone of a democratic state (Leveson 2012, 4), but newspapers have also been criticised, with many pointing out the reliance on elite sources (see Davies, 2011; Herman \& Chomsky 2008; Bennett 1988) and the Leveson inquiry into 
the British press mentioned "there have been far too many occasions ... when [the press'] responsibilities ... have simply been ignored" (Leveson 2012, 4).

In 1979, Herbert Gans called for the news media to reduce its reliance on elite sources and become more multi-perspectival, better representing other sectors of society. Over the last decade new technologies have provided new ways for citizens to participate in the news. This has been embraced by some, for example the Guardian editor quoted by Hermida et al. $(2011,15)$ as saying they want to "make lots of voices, including ones we don't agree with, heard". Others have proven reluctant to embrace these new possibilities, with Thurman $(2008,8)$ quoting Independent.co.uk editor Martin King describing the users of The Independent's now closed messages boards as "a bunch of bigots who were shouting from one side of the room to the other and back again". This leaves a situation where some news outlets are very open to reader participation and approach the ideal of multi-perspectival news, while others involve their audience in a superficial way while retaining overall control of the process.

The terms mentioned have been applied to such a wide range of systems with differing functionality and levels of audience participation that they provide little information about those systems. This leaves one big question unanswered: How much power do citizens actually have in defining and shaping what is news? To answer this it is important to be able to determine which outlets involve the audience meaningfully and which merely claim to do so.

Ways to describe the extent of participation have been explored in other domains. For example in 1969, Arnstein proposed her "ladder of citizen participation", a typology of citizen participation looking at social programs (Arnstein 1969). Arnstein discussed the difference between the "empty ritual of participation" and "real power needed to affect the outcome", bemoaning the use of euphemisms such as "self-help" and "citizen involvement" as clouding the issue and making it more difficult to judge how much power is actually being given to citizens. This is a similar issue to the proliferation of terms used to describe online news systems. However, Arnstein's work does suggest a way forward, as the ladder of citizen participation focuses on what actually happens rather than the terms assigned.

Inspired by this approach, in this paper we conduct an analysis of 32 online news systems, comparing them in terms of how much control they give users at each stage of news production. Our objective is not to classify them, but to systematically analyse them to reveal the genuine landscape of citizen participation. In order to fully understand the process a news story goes through we then provide examples of how the online chain of news communication works by tracking several specific stories as they move through this landscape. Analysing the systems in this way will allow us to meaningfully judge whether online news systems are fulfilling the ideals implied by the terms used to describe them.

The key questions that we will attempt to answer are:

(1) How much power is being given to citizens through online news systems?

(2) What is the relationship between those systems that are more open and those that are less?

We start by reviewing the literature on online news production, and in particular examining the terminology used by scholars and practitioners. We then provide an overview of our methodology, present the 32 systems selected for study and detail the eight-stage framework used for our analysis. The analysis itself is then presented in the form of a matrix of citizen participation in each stage, and a landscape constructed from 
the profile of each stage. We then look at four specific stories in detail to get a more complete view of how news stories move and evolve across this landscape. Finally, the paper concludes by returning to our research questions and exploring directions for future work.

\section{Background}

In 2000, the UK Labour government said of the web that "the explosion of information has fuelled a democratic revolution of knowledge and active citizenship" (quoted in Fenton [2010]). However, at this time the web was still a read-only medium where few actors created content and the rest consumed it. Technology began to fulfil this vision more completely in the mid 2000s with the advent of Web 2.0, a term popularised by Tim O'Reilly to describe web technologies which allow for more interaction than the static web pages which preceded them, allowing users to produce content rather than simply consume it (O'Reilly 2005). Examples of Web 2.0 include blogs, wikis, and online social networks.

More recently there has been a push for "open data", for governments and public institutions to make data publically available in machine-readable formats (for an overview of open data see Shadbolt \& O'Hara [2013]). This shows a progression towards openness and the involvement of citizens in the processes that concern them. This is the same trend that has led to citizen journalism as it exists today.

The term "citizen journalism" has been used broadly to describe everything from bloggers producing independently researched stories to people sharing news on social networks (Robinson \& Deshano 2011). Some have attempted to make a distinction between "true" citizen journalism free from the influence of professional journalists on one hand, and citizen participation in professionally produced news stories on the other. For example Nip (2006) went as far as to identify five levels of citizen participation in journalism, in order of increasing openness: traditional journalism, public journalism, interactive journalism, participatory journalism, and citizen journalism.

A previous set of categories proposed by Lasica (2003) used the term "participatory journalism" to describe the idea of citizen participation in journalism and categorised it as falling into six categories: audience participation at mainstream outlets, independent news sites, full-fledged participatory news sites, collaborative media sites, other kinds of "thin media", and personal broadcasting sites. Of these, personal broadcasting sites have grown so much in the years since Lasica's paper that none of the sites we analyse in this paper that we would categorise as personal broadcasting existed when Lasica proposed these categories.

Bruns (2005) took a different approach when he examined "gatewatching", the process of monitoring the output of other news systems in order to produce news output. He analysed and categorised several online news systems in terms of the gatewatching processes they use, proposing a continuum ranging from "closed news", through collaborative news sites and news-based blogs, and on to non-news sites that sometimes report news such as personal blogs and homepages.

The terms used by Nip, Lasica, Bruns, and others are used inconsistently throughout the literature and this reduces the usefulness of these terms when discussing modern journalistic endeavours. To demonstrate this, Figure 1 shows how these terms have been applied to a range of technical systems that support news. A total of 66 papers from 52 journals, conferences, and books were analysed (ranging from Journalism Studies to The World Wide Web Conference). The analysis is not fully comprehensive but it does show that some systems are described by a number of different terms, sometimes by terms that seem contradictory. For example, The 
Huffington Post was described as "citizen journalism" by Bruns \& Highfield (2012), but was described as "mainstream news" by Kwak et al. (2010); and Slashdot has been described by a range of terms including "citizen journalism" (Bruns \& Highfield 2012), "participatory" (Domingo et al. 2008, 331), "social news" (Lerman \& Ghosh 2010), "alternative" (Bruns 2006) and "the press" (Lih 2004). When producing the matrix we have excluded systems that were described by less than two terms, and terms that were used in less than two publications.

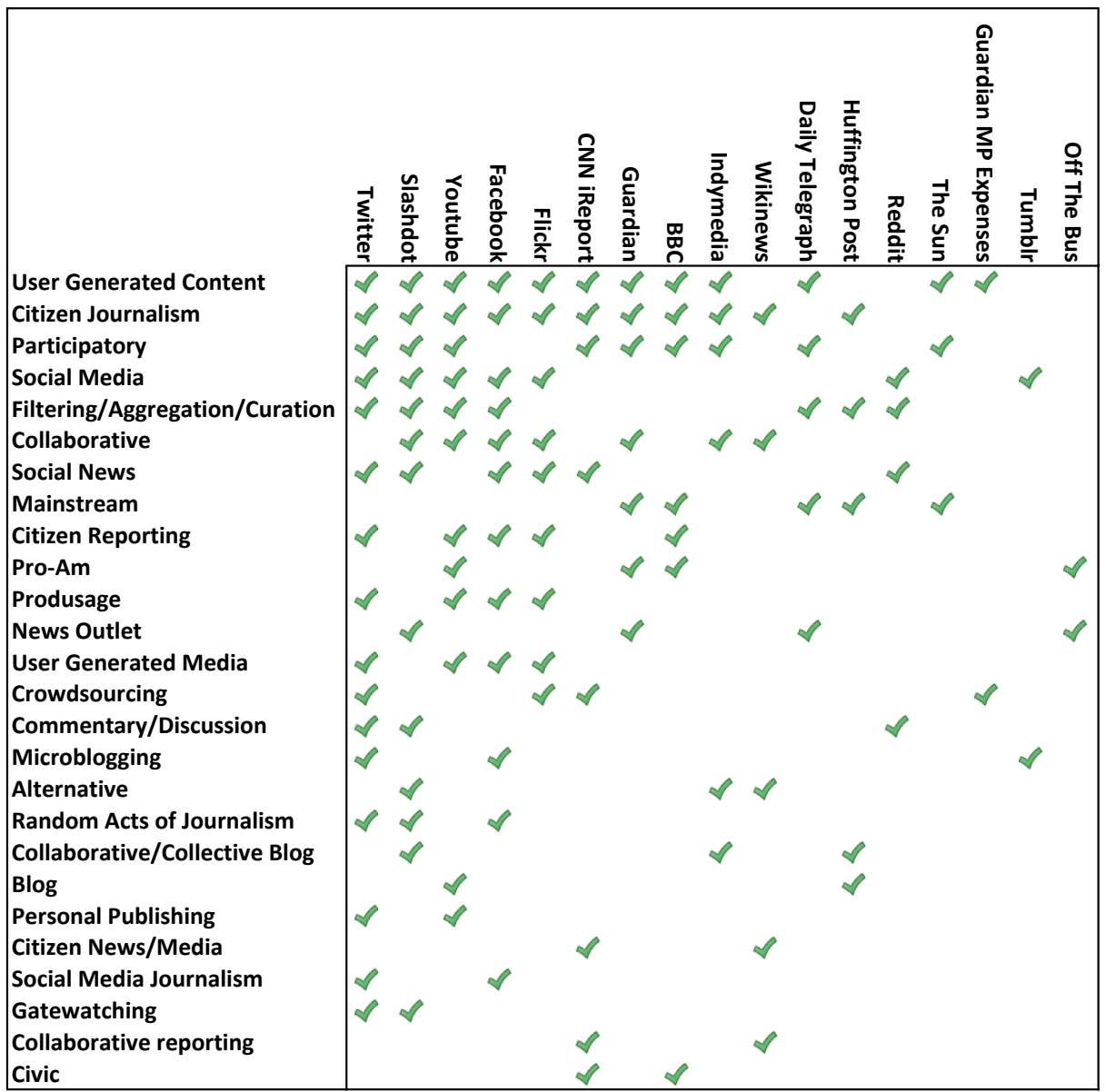

Figure 1: Terms used to refer to technical systems used for news

This confusion of terms makes it difficult to discuss and compare tools and approaches, and so in this paper we attempt a different approach and use a model of the news production process to reveal a spectrum of participation from the more open to the more closed, comparing the systems in terms of who has control of each stage. We believe that this is a more sophisticated and robust view than those allowed by a set of discrete categories.

\section{Methodology}

We have shown that comparing systems based on the terms used to describe them does not give us meaningful comparative power. In the spirit of Arnstein's ladder, in this analysis we compare the systems based on how much power they give to readers rather than on terms assigned to them or on a feature list. We have adapted the methodology used by Domingo et al. (2008) to allow us to apply it to a wider range of modern 
systems. We view the distinction made by Domingo et al. between those contributing to a stage and those managing it as particularly important, taking into account Lukes' (1974) three dimensional view of power, whereby power is exercised through control of the agenda, not necessarily through individual actions or decisions.

When Bruns (2005) analysed participatory news websites, he used a simple model of news production with three stages: Input, Output, and Response. Domingo et al. (2008) built on this in their study of newspaper websites, using a six-stage model to allow for more granularity in the analysis. The stages used were Access and Observation, Selection/Filtering, Processing/Editing, Distribution, and Interpretation. We have used these stages as the basis for the ones used in our analysis, but have made some changes to account for specific features of our analysis.

Some initiatives allow one community to feed into another, for example CNN iReport feeding into CNN's other properties. In these cases it is important to look at how news is distributed both within a community and outside of it. To represent this we separated the distribution stage into "on-site prominence" and "off-site prominence". Note that off-site prominence refers only to features inherent to the system in question, and not on the ability of users to share news articles independently. It is also important to distinguish between the initial interpretation (often the written article itself, though on CNN iReport staff can add their own interpretation which sits above the article), the ability for readers to add their own interpretation via comments, and the ability to decide the prominence of those comments.

Some systems allow for multiple paths through a stage, and this is represented in our analysis by splitting the cell vertically, showing the most common path on the left and the alternative path to the right. For example, prominence on Twitter is primarily decided by members (using follows and retweets), but advertisers can also pay to make their messages more prominent.

The openness of each stage was determined by reading the privacy policies and terms of use of each system, and where this was ambiguous, looking for examples of staff filtering, modifying, or censoring reader contributions. In all cases we have assumed that staff will ensure that content complies with local laws (e.g. removing copyright material) and have not counted this as staff control unless staff are also exercising other moderation powers. We have also ignored the fact that at a technical level staff have overall control in all cases due to being in control of the technological infrastructure.

Table 1 shows how we have expanded Domingo's stages to provide an eightstage framework for our analysis, and shows the criteria for openness that we applied.

\begin{tabular}{|l|l|l|}
\hline Original (Domingo et al. 2008) & Stage for Our Analysis & $\begin{array}{l}\text { Criteria for Analysis } \\
\text { Who is able to submit raw data } \\
\text { into the system? }\end{array}$ \\
\hline Access and Observation & Access and Observation & $\begin{array}{l}\text { Who decides which data is } \\
\text { turned into stories? }\end{array}$ \\
\hline Selection/Filtering & Selection/Filtering & $\begin{array}{l}\text { Who produces the stories from } \\
\text { the raw data }\end{array}$ \\
\hline Processing/Editing & Processing/Editing & $\begin{array}{l}\text { Who decides } \text { which stories users } \\
\text { see when they are on the site? }\end{array}$ \\
\hline Distribution & On-site prominence & $\begin{array}{l}\text { Who decides } \text { which stories get } \\
\text { pushed to parent } \text { sternal sites? }\end{array}$ \\
\cline { 2 - 3 } & Off-site prominence & $\begin{array}{l}\text { Who provides the first } \\
\text { interpretation seen } \text { when viewing }\end{array}$ \\
\hline Interpretation & Initial Interpretation &
\end{tabular}




\begin{tabular}{|l|l|l|}
\hline \multirow{2}{*}{ Commenting } & the story? \\
\cline { 2 - 3 } & $\begin{array}{l}\text { Who is allowed to provide } \\
\text { additional interpretation in the } \\
\text { form of comments? }\end{array}$ \\
\cline { 2 - 3 } & Comment Prominence & $\begin{array}{l}\text { Who moderates and decides the } \\
\text { prominence of those comments? }\end{array}$ \\
\hline
\end{tabular}

Table 1: Mapping of the stages used by Domingo et al. to our analysis stages and the criteria for analysis.

\section{Defining Levels of Participation}

In their analysis Domingo et al. categorised each stage as closed, slightly open, moderately open, or very open, but we have chosen to be more explicit about who has control in each stage. We use five participation levels, in decreasing order of individuals' personal investment in the system: Staff, who have an official association with the system; Paid, who pay for privileged access (e.g. advertisers, subscribers); Privileged, who without paying for it have been given extra privileges; Members who have registered for an account; and Public which includes everyone else.

\section{Sorting the Framework}

The results of our analysis were placed in a matrix mapping each system against each of the eight stages. We sorted the systems according to how open they were overall, effectively turning the matrix into a spectrum where on the left are systems more tightly controlled by staff, and on the right are systems which offer more power to users. We did this by sorting based on the number of stages in each system managed by staff (or unimplemented), then by the number of stages managed by paid members, then by the number of stages managed by privileged members, and so on.

The decision to treat an unimplemented stage as almost as closed as a staffcontrolled stage was made in order to keep the sorting simple while giving a meaningful order to the systems. In reality whether a non-existing stage should be considered open or closed depends on which stage it is. For example, not having a filtering stage could be seen as open, but not having a commenting stage could be seen as closed. This should be looked at in future work.

\section{Selection of News Systems}

In selecting the systems to be analysed, we assembled a list following a literature search and an analysis of popular online websites. By "news system" we mean a socialtechnical system used for news. This means that the same technical system can appear more than once (for example Republic on Facebook and BBC News on Facebook) because they are used in a different social context.

To ensure a broad range of technical systems covered, we ensured that we identified examples of social news (Reddit, Slashdot), social media (Twitter, Facebook, Tumblr, Youtube, Flickr), mainstream citizen journalism websites (CNN iReport, Fox uReport, Al Jazeera Your Media, MSNBC FirstPerson), independent news websites (Indymedia UK, Wikinews, Wikileaks), mainstream news websites (The Guardian, BBC News, Daily Mail, The Sun, The Daily Telegraph), blogs (Wordpress, Blogger, Gawker), forums (vBulletin) and one-off newsgathering projects (The Huffington Post's OffTheBus project, The Guardian's MP's Expenses investigation). 
We have attempted to take a representative look at citizen participation in journalism, however due to time limitations we have looked only at English language websites, primarily American and British.

\section{Case Studies}

When performing the analysis, it became clear that though news does typically travel sequentially through the stages, it also appears to travel across systems, for example appearing on Youtube before being discussed on Reddit and then mentioned on The Telegraph. We used case studies of four stories that reached the public to explore this in more depth. The case studies were chosen to represent a range of different types of stories:

- "Your thoughts on Hugo Chavez" was an invitation to contribute instigated by a large media company

- "Reddit Bomb" was an investigation by an informal group who produced their own press releases

- "My tram experience" started as an individual's report of a train journey with seemingly no intent to make news

- "Transsexuals should cut it out" began with a story in a traditional newspaper, which was then discussed on social media.

Each of these shows a different way that news travels through news-making systems. These case studies have been limited to news of short events, avoiding longrunning engagements such as war. This was to make it more feasible to collect and analyse the output generated about the event, and to allow us to more precisely point to the events that caused particular stories. Even with this reduced scope it is still not possible to collect all articles about an event and so we have focused primarily on articles posted on the systems analysed in this paper.

\section{Building the Landscape}

The completed framework can be seen in Figure 2, and we have also taken inspiration from Bruns' 2006 book "Gatewatching" and plotted each stage on a line graph in Figure 3 to allow us to look across the spectrum to more easily spot patterns.

In this section we first look at each stage in turn, and then reflect on what the analysis shows us as a whole. 


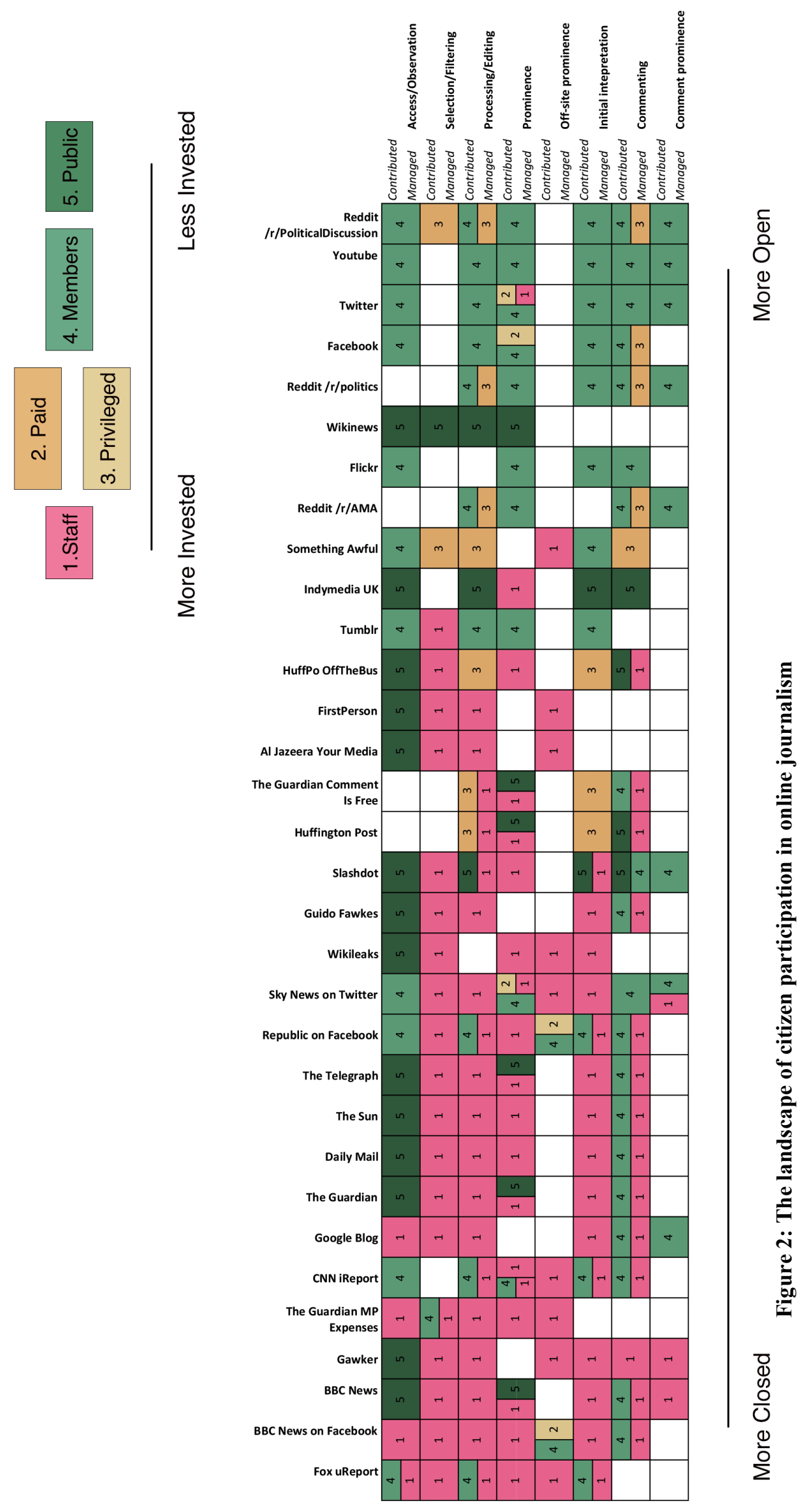




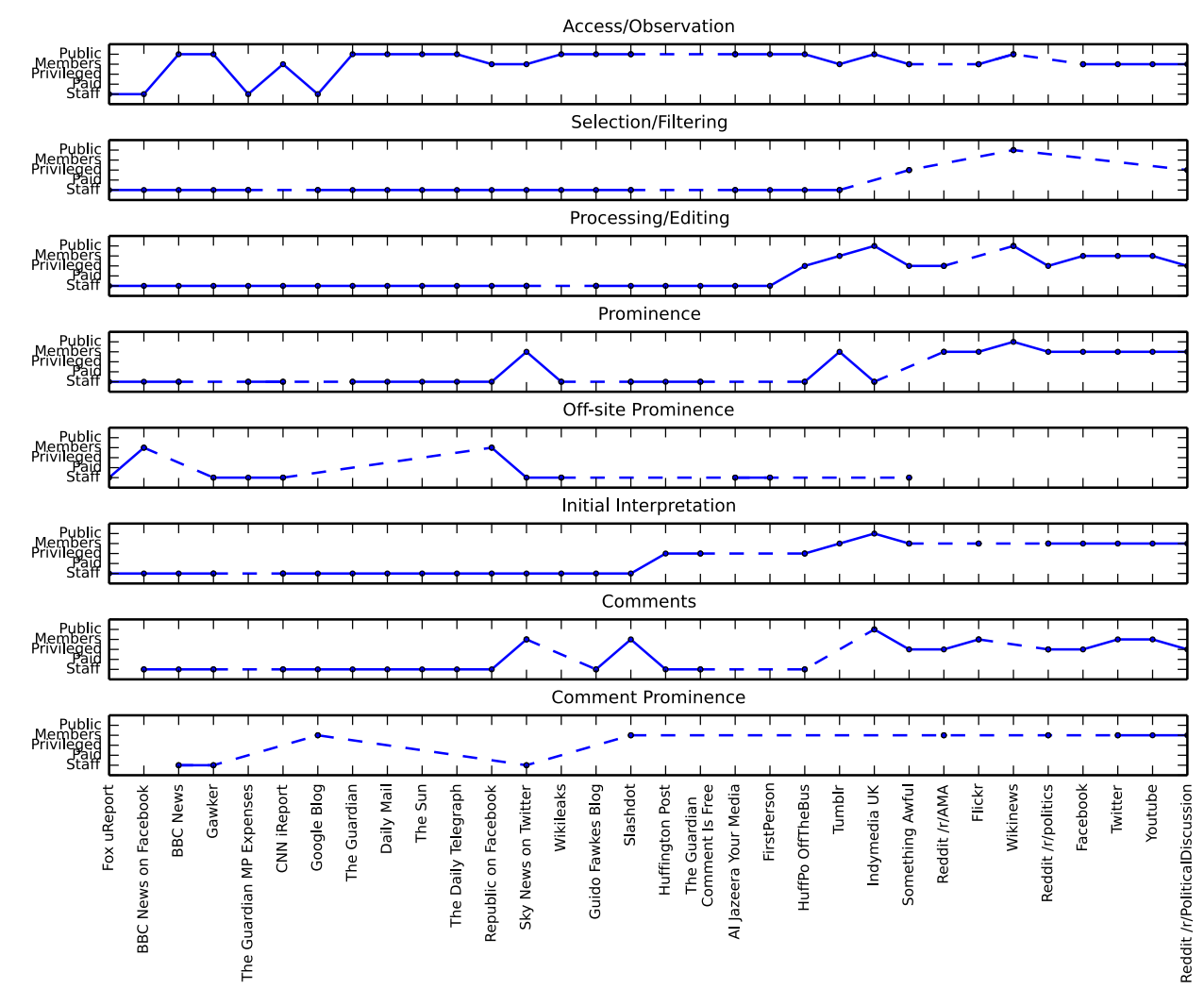

Figure 3: Openness by stage with systems ordered from most-closed to most-open

\section{Access/Observation}

In the Access/Observation stage we look at who is able to submit data into the system. Many systems allow for either the public or members to submit information on any topic (although Fox uReport only allows data submission on pre-approved topics).

\section{Selection/Filtering}

At this stage it is decided which data is turned into stories. The only system considered open at the filtering stage was Wikinews, which allows the public to decide which stories get written. The PoliticalDiscussion Reddit community has privileged users (moderators) decide if a topic is suitable for discussion, and every other system which has a filtering stage has staff either in total control or managing the work contributed by others.

\section{Processing/Editing}

The processing/editing stage involves the production of stories from the data. For Reddit's politics community, where users link to existing stories rather than writing their own, this stage refers to the creation of a link rather than the production of a story.

\section{Distribution}

Distribution has been split into on-site prominence and off-site prominence. 
On-site prominence represents how it is decided what users see on the site, the options we saw here were: decided by members via voting or "following" sources, decided by staff, decided by advertisers, or shown in chronological order. This is different to personalisation, where prominence is altered but only for a single individual.

Off-site prominence is used for sites that feed into other sites (CNN iReport, Fox uReport, etc.) where it represents how news gets selected to appear on the external site. It is also used with systems that sit atop other systems (BBC News on Facebook and Sky News on Twitter) where it represents how news spreads to the wider network. In the case of Wikileaks it refers to Wikileaks staff collaboration with mainstream news outlets.

\section{Interpretation}

The initial interpretation represents the first interpretation seen when viewing the story (the "lead" in the inverted pyramid structure of news). Typically this is decided by the same group who contributes to the processing/editing stage, but in the case of iReport, staff are able to place their own interpretation on an article that is shown before the article itself.

Staff typically moderate comments, but in some cases this moderation power is given to members. The prominence of comments is usually decided either by chronological order or member votes. BBC News is an exception in that staff members choose to feature certain comments to be shown before others.

\section{Overview}

Looking across the systems from most-closed to most-open, we can see that the access/observation stage is open even on many of the more closed systems, and the commenting stage opens up relatively early. We can see that the other stages (except for off-site prominence which will be discussed shortly) tend to stay closed for much longer. This indicates that journalists are still reluctant to give up any real gatekeeping authority, and is consistent with previous research (e.g. Hermida et al. 2011; Thurman \& Hermida 2010; Bowman \& Willis 2003).

Off-site prominence in most cases is either missing (because the system isn't feeding into or sitting atop another system) or controlled by staff. The two cases where members control this stage are cases where the organisation has no choice because of the underlying system (Twitter and Facebook).

The patterns here are less clear than those shown by Bruns (2005) because we are looking at individual systems rather than broad categories. This further demonstrates the limited utility in trying to categorise these systems when there are so many differences within each category.

We can see that there is a lot of variety in the ways systems allow for citizen participation and there are very few clear groupings. The "closed news" providers are all very similar, with The Guardian, Daily Mail, Sun, and Daily Telegraph having the same openness profile, and BBC News differing only in that it has staff feature comments. The Guardian's Comment Is Free and The Huffington Post also share the same profile, whereby non-staff members contribute after being approved by staff. Al Jazeera Your Media and MSNBC First Person share a profile, both offering little more than a submission form. Social media websites Facebook, Twitter, and Youtube are very similar, and would fit well into the "Personal homepages" category in Bruns' continuum and Lasica's "Personal publishing" category. The rest of the systems 
however are very difficult to categorise, with too many meaningful differences to group together.

Several of the systems in the framework would not typically be considered news systems at all. In particular, sites like Youtube are not usually considered news sites but we can see from the framework that Youtube supports almost the entire news-gathering process, and suggests that perhaps there are cultural rather than technical reasons that Youtube is not usually considered a news site.

It is interesting that $\mathrm{CNN}$ iReport has a very similar profile to traditional news organisations, and Fox uReport is actually more closed than traditional news organisations. Though at first glance they appear to be citizen led systems, the analysis reveals that these systems just attempt to reproduce what is already happening on the web within a single system that CNN/Fox can control. Kperogi (2011) made this point in his 2011 analysis of CNN iReport where he argued that "online citizen media are actually being coopted into the culture and conventions of mainstream media practices".

\section{Case Studies}

It is clear that stories do not exist within one system, but rather move and evolve as the story develops. To investigate the relationship between the more open systems and the more closed systems in this process we will now look at the spread of four specific stories in more detail. In our work we are keen to investigate the relationships between systems rather than the reasons why each individual system is the shape that it is. To achieve this we have focused on individual news stories rather than news systems.

The following sections present a summary of each case study followed by a discussion. We present each case study along with a timeline showing how the story progressed. On the timelines, we have only indicated where a particular story appeared, and have not attempted to establish the source of each appearance. Work in this area has been performed for blogs (see Adar, et al., 2004) but performing similar work on the wider web was beyond the scope of our analysis.

\section{Case Study 1: Your Thoughts on Hugo Chavez}

When Hugo Chavez died on March $5^{\text {th }} 2013$, CNN used their iReport platform to solicit opinions on his life. They created an assignment titled "Your thoughts on Hugo Chavez" in English and Spanish and gave people ten days to reply. Over the next ten days, 167 reports were filed (though since then 10 have become unavailable with no explanation). Of the 157 reports still available, 95 are in English and 62 in Spanish.

Most reports posted on iReport are not vetted and CNN make no claims as to their accuracy. Once vetted by CNN, reports are stamped "CNN iReport" and are cleared to be used in other CNN outlets. Of the 157 submitted reports, 10 English and 14 Spanish reports were approved for use in CNN's other outlets. Due to the scope of our study we will only look at the English iReports here.

We scraped all articles on CNN.com posted between March $5^{\text {th }}$ and May $1^{\text {st }}$ that were returned by a search for "Chavez", we also scraped all CNN show transcripts available on transcripts.cnn.com between these dates. With this data we searched for instances of the word "ireport", and for the titles, authors, and key parts of the description of each vetted story. We have placed the ten vetted English language iReports on Table 2 alongside the number of views, the number of Facebook shares, and the places where CNN used the iReport. We have also placed the usage of the English iReports on Figure 4, which shows the short period of time that the reports got used. 
We can see that one report "10 reasons why I will not miss Chavez", an English post by Venezuelan iReporter Pancho49, received 203,000 views compared to the next highest with 4,300. Despite this, the data shows that other less popular stories were featured more prominently by CNN. Some of the stories, despite being vetted, are not mentioned in any of the materials we collected. This may mean they have not been featured by CNN at all, or that they were featured on a CNN show that does not publish transcripts.

There does not seem to be any relationship between the views or recommendations an iReport receives and whether it gets vetted. One iReport, "The end of a Dictator" was vetted having received only 95 views and 2 recommendations, whereas "Who are crying for Hugo Chavez?" was not vetted despite receiving 3322 views and 377 recommendations.

\begin{tabular}{|c|c|c|c|}
\hline Title & Views & $\begin{array}{l}\text { Facebook } \\
\text { Recommendations }\end{array}$ & Used \\
\hline 10 reasons why I will not miss Chavez & 202865 & 38136 & 2 webpages \\
\hline Chavez: a champion for the poor & 4283 & 26 & $\begin{array}{l}1 \text { webpage } \\
1 \text { TV show }\end{array}$ \\
\hline Honors the memory of Hugo Chavez in Paris & 3190 & 53 & 1 webpage \\
\hline $\begin{array}{l}\text { Rest In Peace President Hugo Chavez, You Are } \\
\text { The Hero Of The Poor }\end{array}$ & 1020 & 10 & None \\
\hline What would happen soon in Venezuela & 982 & 20 & $1 \mathrm{TV}$ show \\
\hline $\begin{array}{l}\text { Remembering the Late Venezuelan Pres. Hugo } \\
\text { Chavez }\end{array}$ & 758 & 24 & $1 \mathrm{TV}$ show \\
\hline Chavez Dead- Hope born & 543 & 2 & 3 webpages \\
\hline $\begin{array}{l}\text { Most Famous Venezuelan President Hugo } \\
\text { Chavez dies! }\end{array}$ & 436 & 45 & None \\
\hline Chavez is not the way for Latin America & 147 & 1 & None \\
\hline The end of a Dictator & 95 & 2 & None \\
\hline
\end{tabular}

Table 2: English iReports posted in response to "Your thoughts on Hugo Chavez" 


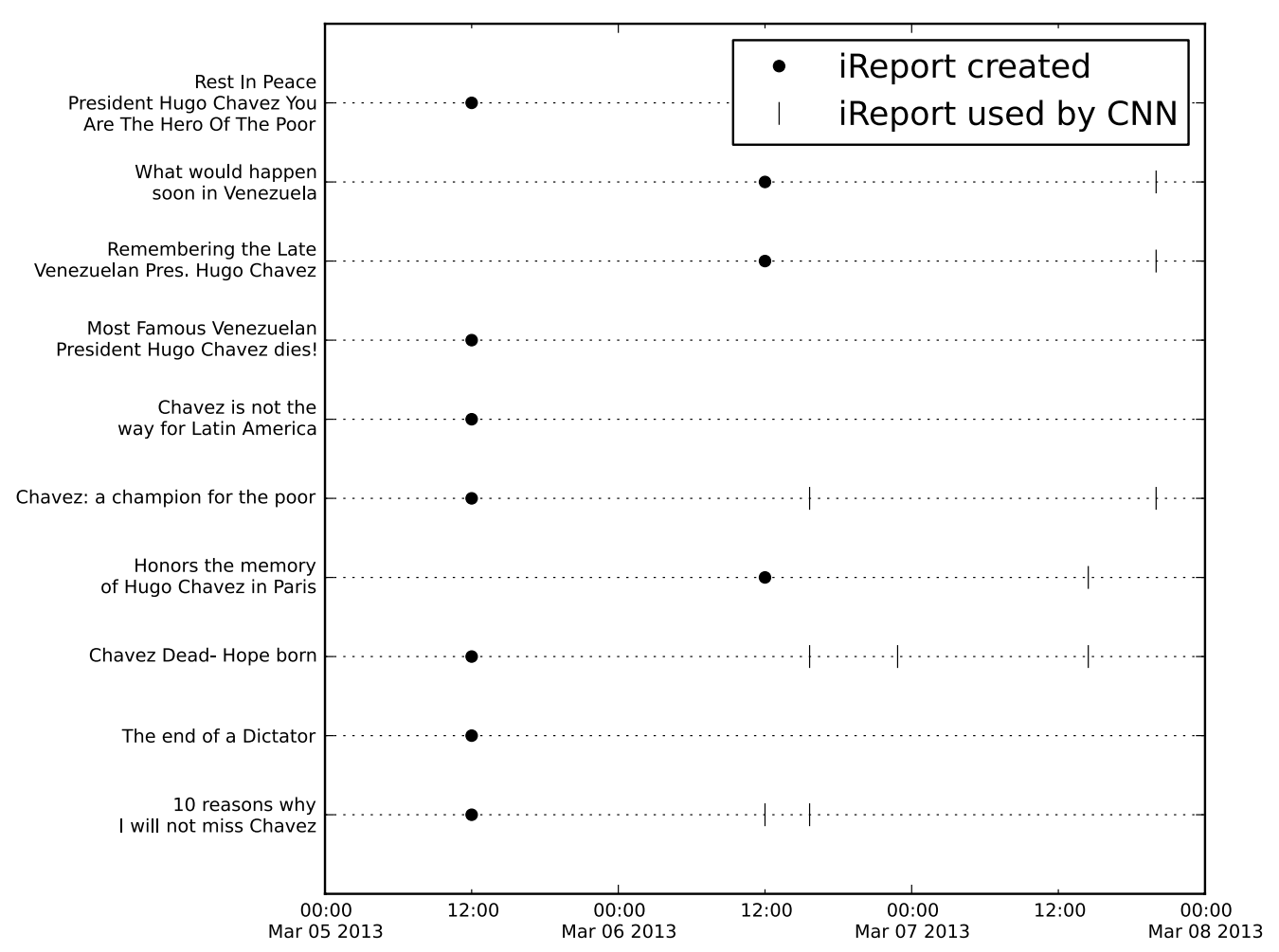

Figure 4: Timeline for Case Study 1, Your thoughts on Hugo Chavez

\section{Case Study 2: Reddit Bomb}

On September $29^{\text {th }} 2011$, CNN's Anderson Cooper highlighted the "jailbait" section of Reddit (/r/jailbait), a community used for posting sexually suggestive photographs of adolescents. This led to a split in the Reddit community between those who wanted $/ \mathrm{r} / \mathrm{jailbait}$ shut down and those who felt that it should be permitted under the aegis of free speech. The latter group included Reddit general manager Erik Martin who said to $\mathrm{CNN}$ "We're a free speech site and the cost of that is that there's stuff that's offensive on there" . However on October $9^{\text {th }}$ it was discovered that some users were using this section to trade child pornography and in response Reddit shut the community down.

On rival online community Something Awful there existed a discussion where Reddit was mocked. On February $2^{\text {nd }} 2012$ participants noticed a "preteen girls" section (/r/preteen_girls) of Reddit which had been set up to replace /r/jailbait. Much discussion then focussed on this community and others like it. The participants began to discuss what they could do about these communities and one suggestion, made repeatedly, was to encourage a follow-up investigation by the media, with suggested outlets including CNN, The Huffington Post, and MSNBC.

On February $12^{\text {th }}$, the first draft of a press release known as the "Reddit bomb" was created. Members of Something Awful began discussing the press release with members of the "ShitRedditSays" (SRS) section of Reddit (a community which

1. As quoted on Anderson Cooper 360, CNN, September $29^{\text {th }}, 2011$ 
discusses sexism, racism, homophobia, etc. on other Reddit communities). They requested that the SRS members compile screenshots of these communites and between the two communities they began sending the press release to news outlets, churches, politicians, the FBI, police, Reddit advertisers, and spreading it via social networks. Less than six hours after they began spreading the press release, Reddit introduced new rules explicitly banning sections focusing on the sexualisation of children which satisfied the majority of the contributors and discussion moved on to the response of Reddit users to the change.

News of this policy change appeared in a number of places including The New York Observer, Gawker, MSNBC, and The Huffington Post. Figure 5 shows the time that these articles appeared. This story was reported much more heavily in tech-focused media than in mainstream news outlets, and it appeared in only a small number of the systems we placed on our matrix. Many of the outlets it appeared in are online news websites running on blog platforms, and they share similar openness profiles. We did not place all of these systems on the matrix due to issues of space, and the outlets shown in Figure 5 can be assumed to be similar in profile to Gawker if they are not on the matrix themselves.

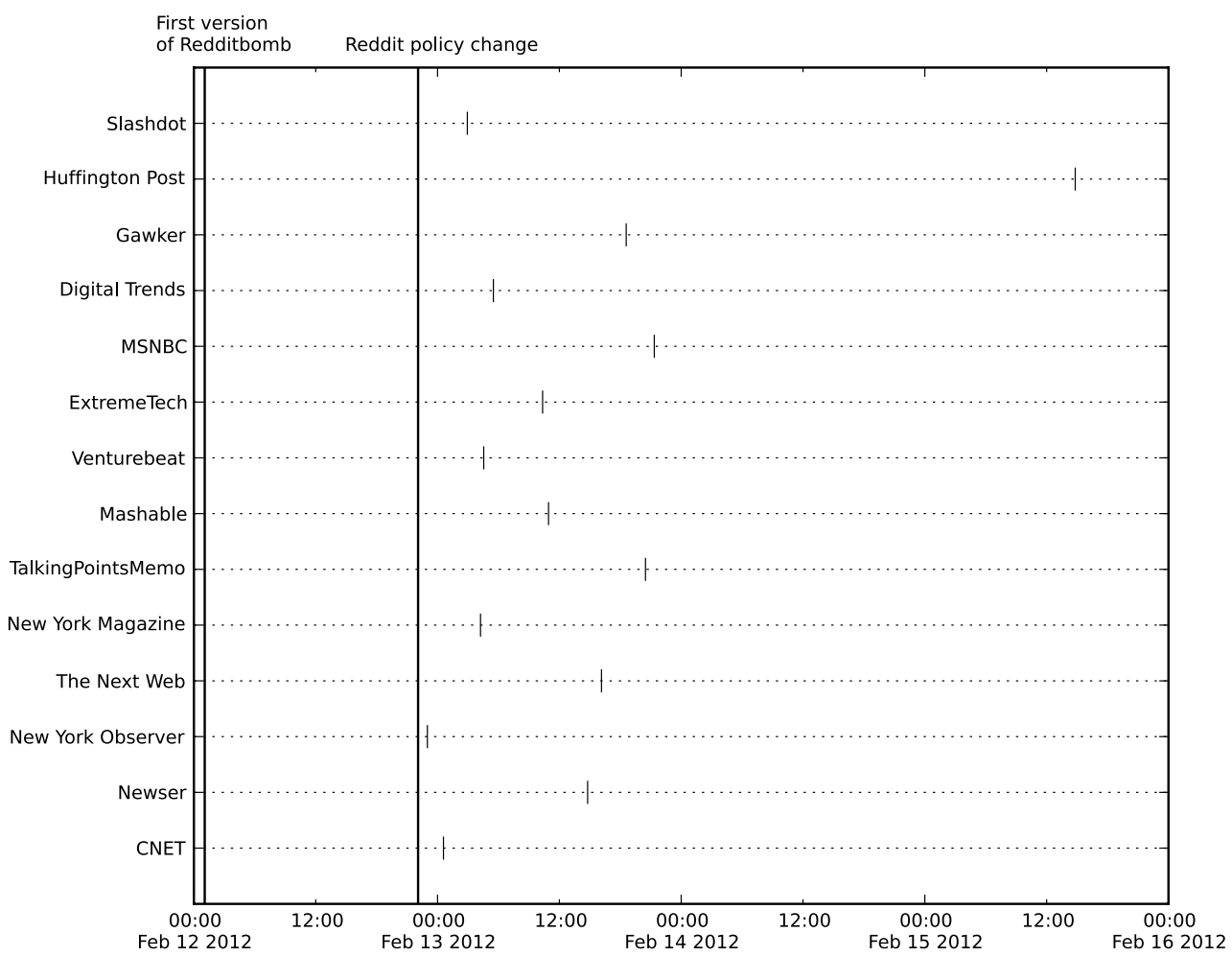

Figure 5: Timeline for Case Study 2, Reddit Bomb

\section{Case Study 3: My Tram Experience}

On November 27th, 2011, Youtube user ladyk89 uploaded a video titled "My Tram Experience" which showed a woman racially abusing passengers on a London tram. The video was discussed on Twitter where \#MyTramExperience became a trending topic and discussion of the video appeared on many other websites. At 2:44am, the video was posted to Reddit under the title "I feel sorry for the kid - Racist woman on UK tram". 
The Telegraph published a story about the video at 3:21pm, mentioning "many reacting angrily and calling for the woman to be arrested and charged", reflecting the sentiment in the Youtube comments without drawing attention to any comment in particular. It also quoted the description of the video provided by ladyk89 ("British woman on London transport complaining that Britain is nothing now that ethnic minorities are in her country"). The Huffington post also wrote a piece on the video at $3: 44 \mathrm{pm}$ quoting Youtube users and linking to the video.

After the woman's arrest was announced by the British Transport Police many more outlets picked up the story, including the Guardian, the Daily Mail, and the BBC. Figure 6 shows when the story appeared on several of the systems in our analysis.

[Figure 6 near here]

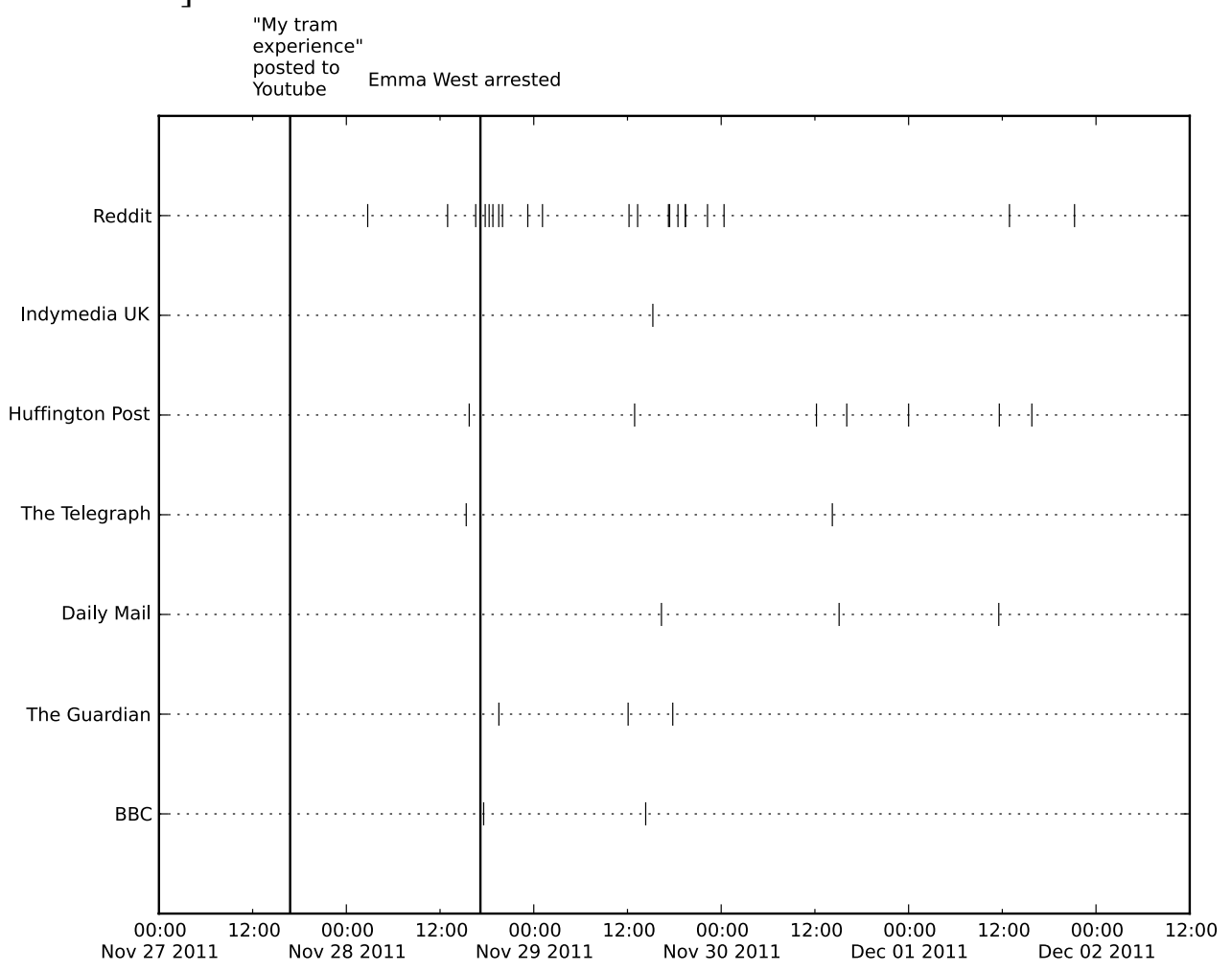

Figure 6: Timeline for Case Study 3, My Tram Experience

\section{Case Study 4: Transsexuals Should Cut It Out}

On January 8th 2013, New Statesman published an article by Suzanne Moore titled "Seeing red: the power of female anger". The article itself was about the UK recession's affects on women and towards the end of the article she wrote that women "are angry with ourselves for not being happier, not being loved properly and not having the ideal body shape - that of a Brazilian transsexual".

The New Statesman Culture Twitter account tweeted about the article at 10am and received initially positive responses. At 1:17pm,@jonanamary tweeted "Was loving this piece by Suzanne Moore on women's anger, then wham, SURPRISE TRANSPHOBIA. Ugh.” followed by a tweet directed at Suzanne Moore's Twitter account explaining what she felt was transphobic. Suzanne Moore responded and the two argued for some time before others got involved. 
The article was analysed on the Huffington Post and in many blogs and alternative media outlets. Suzanne Moore wrote a follow up article in the Guardian and this lead to further arguments both in the comments of the Guardian article and on Twitter, which led to Suzanne Moore deleting her Twitter account on January 11th.

On January 13th, Julie Burchill wrote an article in The Observer defending Suzanne Moore. This piece included references to transsexuals as "dicks in chick's clothing", "trannies" and "shemales", and was generally inflammatory. This caused discussion on Twitter and analysis on blogs, including blogs on The Independent and The Telegraph websites. After backlash against The Observer, the article was removed and an apology put in its place. However it was mirrored on one of The Telegraph's blogs.

A timeline of this discussion can be seen in Figure 7. We have included a sample of relevant blog articles, tweets, and news articles, and have excluded messages that were not referring to the articles or the discussion surrounding them. The tweets shown on the timeline are those available via Twitter's search API or via Storify.

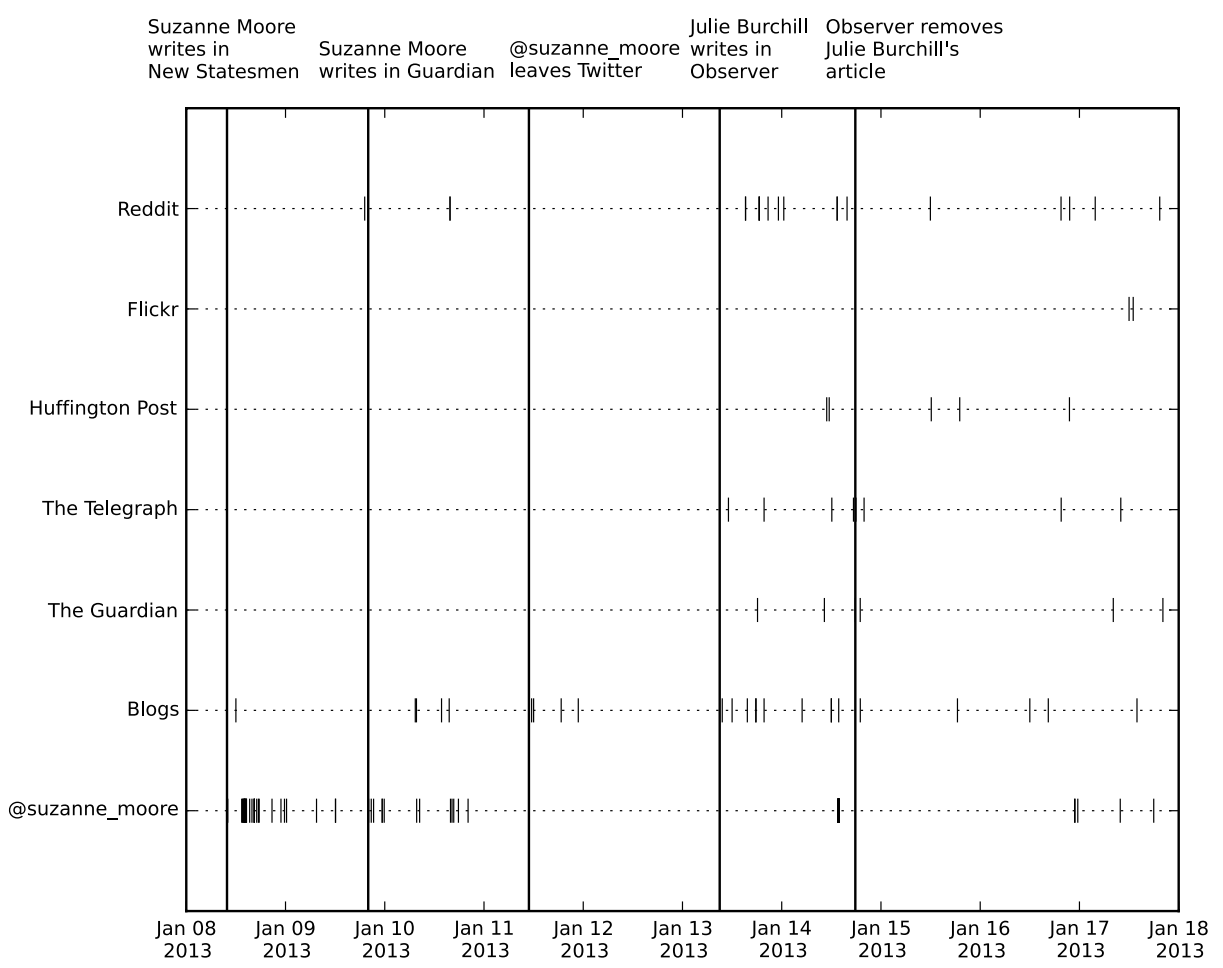

Figure 7: Timeline for Case Study 4, Transsexuals Should Cut It Out

\section{Discussion}

Whereas the landscape allows us to compare news systems in general terms, the case studies allow us to see how they relate to one another. In the first three case studies the story moved from the more open systems to the more closed systems but in the final case study the story actually started in a relatively closed system, before being discussed on a more open system, causing further discussions on the closed system, etc. There are many examples of stories that move from open systems to closed systems, and many organisations dedicated to analysing the output of mainstream media (e.g. MediaLens, Biased $\mathrm{BBC}$ ). It is more rare for journalists to comment on the response to their stories in the way that occurred in Case Study 4. 
News values are the factors that influence how newsworthy a particular story is. Though they of course differ by news organisation, several lists have been compiled of the most common news values that are consistent across a particular region. Some of the most commonly used lists include the one by Harcup \& O'Neill (2001) and, the list on which theirs is based, the one by Galtung \& Ruge (1965). In this section we will use the news values proposed in these two lists as a means of analysing what occurred in the case studies, although it remains an open question as to how news values affect online news (Zubiaga 2013).

In the "Reddit Bomb" case study, the forum members showed an understanding of news values when spreading the story, attempting to tailor it to each outlet. For example one user posted "I just sent the Reddit bomb to the Dallas Morning News. I also mentioned that [the administrator of the subreddit] lives in Dallas" indicating an understanding of the relevance news factor. Due to the short amount of time that passed between the creation of the press release and Reddit's response it is unclear if the press release would have been published widely had Reddit not responded, however the fact that none of these articles mention the press release or Something Awful perhaps indicates that they see the change of policy as newsworthy in a way that the existence of the subreddits isn't. This may be because Reddit changing its rules is a simple event to report and fits more neatly into the news cycle than the on-going existence of the subreddits or the on-going campaign (Galtung \& Ruge's "frequency" news value), or it may be that the policy change at Reddit evoked the "reference to elite organisations" news value (within the tech-focused news outlets that reported on this event, Reddit could be considered an elite organisation).

We noticed in some cases that there is a tipping point at which the journalistic activity itself becomes news, or triggers a newsworthy event. For example, the case of Reddit changing their policy, or the "My tram experience" story becoming much bigger once the woman was arrested. In the case of "My tram experience", the arrest gave the press an authority to quote, an effect mentioned by Davies $(2011,120-121)$ when discussing official sources. In the case of "Transexuals should cut it out" the debate that surrounded the original story became a story in itself.

\section{Routes Into The Mainstream}

Through this analysis we found no real route for citizen news to move into traditional outlets, and instead found a chaotic system where it is difficult to predict which stories will move into the public consciousness and which will not.

Even looking at systems such as iReport and uReport that were established specifically to create a route for citizen news to get into the mainstream, the results seem to be very limited. In the case of the Hugo Chavez story we can see that 24 reports were vetted out of 167 filed, not all of those vetted were used by $\mathrm{CNN}$, and those which were used were used in a very small way. It's clear that this system of vetting stories and then promoting them on CNN's other, much more popular, outlets, serves to keep journalists in control of the message.

The large gap in views between "10 reasons why I will not miss Chavez" and the others, despite this apparently not being caused by CNN exposure, shows that there may be some potential for citizens to influence what news gets heard. Of course, despite being the most viewed iReport about Hugo Chavez, it still got viewed by a fraction of 
the 62 million unique visits CNN's news website gets each month ${ }^{2}$. The potential for an iReport to influence opinions needs to be judged with these comparisons in mind.

\section{Conclusions and Future Work}

Due to the importance of news media in society, and the promises that are made for citizen participation in the media, it is important that we have a way of comparing different initiatives. However, innovation in online news progresses so quickly and in so many directions that attempts to rigidly categorise initiatives can be overly constraining to the point that the topology isn't useful. We set out with this research to build a more sophisticated landscape of online journalism, and in particular to compare news systems in terms of their openness. We then used case studies to investigate the relationship between open systems and closed systems. We draw together our conclusions regarding the research questions below.

\section{How much power is being given to citizens through online news systems?}

Through the analysis we found that there are significant differences between systems, even those that seem similar on the surface. We found very few cases where different systems have the same openness profile, though it is clear that the observation and interpretation stages are open even in many of the more closed systems and the filtering stage remains closed even in many of the more open systems.

We found that by using the more open systems on the right side of the spectrum, citizens are able to influence the entire process of news production and distribution. Where systems don't support the entire process they can be used for the part that they do support, before moving the story to another system to continue the process.

Traditional news outlets are still tightly controlled by journalists, and offer opportunities for citizen contribution only when they can filter the contribution, or where the contribution is clearly separated from the work of journalists. The news outlets' use of social networks does not create more openness as they use these outlets only as an additional distribution channel, and even the news outlets' attempts at open news systems are still relatively closed.

\section{What is the relationship between those systems that are more open and those that} are less?

We used case studies of specific news stories to examine the relationship between news outlets. We found a far more complex situation than appears from just looking at the spectrum. Specifically we found that news stories are not constrained within the landscape to a single system and instead move across systems as the story expands, both moving from open systems to closed systems and from closed systems to open systems.

2. According to CNN pressroom, January, 2013 at http://cnnpressroom.blogs.cnn.com/2013/01/18/cnn-digital-maintains-top-spot-for2012/ 
This is consistent with previous findings. Davies (2011) mentioned how news organisations watch the output of other news organisations, Domingo et al. (2008) stated that the process can stop or loop and that each chain of communication can lead into other chains, and this process of the story moving from one outlet to another is very similar to what Bruns (2005) called gatewatching.

The systems towards the right (more open) side of the landscape are systems usually labelled as "social media" rather than seen as news outlets. Yet as we've discovered through the landscape, they support all of the stages of news production. It is not clear why we label them we differently and this may imply that they are perceived differently to the news systems on the left side of the landscape. These systems tend to have much less structure than traditional news outlets, and looking across the landscape from most-open to most-closed we see that as the systems become more open to public participation the less structure they tend to have and the less they look like "news systems". If online news is to become more participatory while retaining the structure of traditional news it may require an entirely new model rather than simply further opening of existing models. Online news systems do exist that do not follow the process identified by Domingo et al. (2008). These systems tend not to produce a "final" story, instead regularly updating as new information becomes known. This has been referred to as "journalism as process rather than product" (Bradshaw 2007, 7 referring to Lih 2004 \& Bruns 2005) and examples include Live Blogs and Wikis. Our future work will investigate if the models used by these systems can be extended to allow for more public participation while maintaining some of the structure associated with traditional news outlets.

Our analysis reveals a landscape of online news that is complex and intertwined, and that like the government departments when Arnstein described her ladder, mainstream news organisations don't really fulfil the promises they make of citizen participation. Citizens can look to alternative media for this kind of power, but that media lacks the structure and authority of traditional news outlets. It may be that the only way to have both freedom and structure is to embrace novel news production processes, and this is what we intend to explore next. Meanwhile our hope is that our landscape will help to shape the conversation around online news and to move it away from simple categorisation to reveal the more complex picture beneath.

\section{REFERENCES}

Adar, Eytan, Li Zhang, Lada A Adamic, and Rajan M Lukose. 2004. "Implicit Structure and The Dynamics of Blogspace." Workshop on the Weblogging Ecosystem 13.

Arnstein, Sherry R. 1969. "A Ladder of Citizen Participation." Journal of the American Institute of Planners 35 (4): 216-224.

Bennett, W Lance. 1988. News: The Politics of Illusion. New York: Longman.

Bowman, Shayne, and Chris Willis. 2003. We Media: How Audiences Are Shaping the Future of News and Information. The Media Center at the American Press Institute.

Bradshaw, Paul. 2007. "Wiki Journalism Are Wikis the New Blogs." Future of Newspaper Conference, Cardiff, UK.

Bruns, Axel. 2005. Gatewatching: Collaborative Online News Production. New York: Peter Lang.

Bruns, Axel. 2006. "Wikinews: The Next Generation of Online News?" Scan 3 (1).

Bruns, Axel, and Tim Highfield. 2012. "Blogs, Twitter, and Breaking News: the Produsage of Citizen Journalism." Produsing Theory in a Digital World: The 
Intersection of Audiences and Production in Contemporary Theory, 15-32. New York: Peter Lang.

Davies, Nick. 2011. Flat Earth News: An Award-winning Reporter Exposes Falsehood, Distortion and Propaganda in the Global Media. London: Random House.

Domingo, David, Thorsten Quandt, Ari Heinonen, Steve Paulussen, Jane B Singer, and Marina Vujnovic. 2008. "Participatory Journalism Practices in the Media and Beyond: an International Comparative Study of Initiatives in Online Newspapers." Journalism Practice 2 (3): 326-342.

Fenton, Natalie. 2010. New Media, Old News: Journalism and Democracy in the Digital Age. London: Sage Publications.

Galtung, Johan, and Mari Holmboe Ruge. 1965. "The Structure of Foreign News: The Presentation of the Congo, Cuba and Cyprus Crises in Four Norwegian Newspapers." Journal of Peace Research 2 (1): 64-90.

Gans, Herbert J. 1979. Deciding What's News: A Study of CBS Evening News, NBC Nightly News, Newsweek, and Time. New York: Random House.

Harcup, Tony, and Deirdre O’Neill. 2001. "What Is News? Galtung and Ruge Revisited.” Journalism Studies 2 (2): 261-280.

Herman, Edward S, and Noam Chomsky. 2008. Manufacturing Consent: the Political Economy of the Mass Media. New York: Random House.

Hermida, Alfred, David Domingo, Ari Heinonen, Steve Paulussen, Thorsten Quandt, Zvi Reich, Jane B Singer, and Marina Vujnovic. 2011. "The Active Recipient: Participatory Journalism Through the Lens of the Dewey- Lippmann Debate." International Symposium on Online Journalism 1.

Leveson, Lord Justice. 2012. An Inquiry Into the Culture, Practices and Ethics of the Press: Executive Summary and Recommendations. London: The Stationery Office.

Kperogi, Farooq A. 2011. "Cooperation with the Corporation? CNN and the Hegemonic Cooptation of Citizen Journalism Through iReport.com." New Media \& Society 13 (2): 314-329.

Kwak, Haewoon, Changhyun Lee, Hosung Park, and Sue Moon. 2010. "What Is Twitter, a Social Network or a News Media?" World Wide Web 2010. New York: ACM.

Lasica, Joseph D. 2003. "What is Participatory Journalism.” Online Journalism Review. http://www.ojr.org/ojr/workplace/1060217106.php

Lerman, Kristina, and Rumi Ghosh. 2010. "Information Contagion: An Empirical Study of the Spread of News on Digg and Twitter Social Networks." ICWSM 10: 9097.

Lih, Andrew. 2004. "Wikipedia as Participatory Journalism: Reliable Sources? Metrics for Evaluating Collaborative Media as a News Resource." International Symposium on Online Journalism.

Lukes, Steven. 1974. Power: A Radical View. London: Macmillan.

Nip, Joyce YM. 2006. "Exploring the Second Phase of Public Journalism." Journalism Studies 7 (2): 212-236.

O'Reilly, Tim. 2005. "What Is Web 2.0? Design Patterns and Business Models for the next Generation of Software." O'Reilly Media. http://oreilly.com/web2/archive/what-is-web-20.html

Robinson, Sue, and Cathy Deshano. 2011. "Citizen Journalists and Their Third Places: What Makes People Exchange Information Online (or Not)?" Journalism Studies 12 (5): 642-657. 
Schultz, Julianne. 1998. Reviving the Fourth Estate: Democracy, Accountability and the Media. Melbourne: Cambridge University Press.

Shadbolt, Nigel, and Kieron O'Hara. 2013. "Linked Data in Government." IEEE Internet Computing 17 (4).

Thurman, Neil, and Alfred Hermida. 2010. "Gotcha: How Newsroom Norms Are Shaping Participatory Journalism Online." Web Journalism: A New Form of Citizenship, 46-62. Eastbourne: Sussex Academic Press.

Thurman, Neil. 2008. "Forums for Citizen Journalists? Adoption of User Generated Content Initiatives by Online News Media.” New Media \& Society 10 (1): 139157.

Zubiaga, Arkaitz. 2013. "Newspaper Editors Vs the Crowd: On the Appropriateness of Front Page News Selection." World Wide Web 2013 Companion: 879-880. 
Jonathan Scott. Corresponding Author. Web and Internet Science, School of Electronics and Computer Science, University of Southampton, Southampton, UK, SO171BJ.js3g10@soton.ac.uk

David Millard. Web and Internet Science, School of Electronics and Computer Science, University of Southampton, Southampton, UK, SO17 1BJ. dem@ecs.soton.ac.uk

Pauline Leonard. Sociology, School of Social Sciences, University of Southampton, Southampton, UK, SO17 1BJ.pauline.leonard@soton.ac.uk 